\title{
ANALISIS KELIMPAHAN FITOPLANKTON DI PERAIRAN ALANG-ALANG TAMAN NASIONAL KARIMUNJAWA
}

\author{
PHYTOPLANKTON ABUDANCE ANALYSIS OF ALANG-ALANG WATERS \\ CENTRAL JAVA KARIMUNJAWA NATIONAL PARK
}

\author{
Nadhea Oktaviantina Rahmawati, Agus Hartoko \& Nurul Latifah
}

\author{
1Program Studi Manajemen Suumberdaya Perairan, Departemen Sumberdaya Akuatik \\ Fakultas Perikanan dan Ilmu Kelautan, Universitas Diponegoro \\ e-mail : nadheaoktavia05@gmail.com
}

Diterima tanggal: 20 Mei 2020 ; diterima setelah perbaikan: 26 Agustus 2021 ; Disetujui tanggal: 30 Agustus 2021

\begin{abstract}
ABSTRAK
Tujuan dari penelitian ini adalah untuk mengetahui kelimpahan fitoplankton pada ekosistem lamun dan lepas pantai perairan Alang-alang Karimunjawa serta faktor-faktor yang mempengaruhi. Penelitian ini dilaksanakan di Perairan Alang-alang Karimunjawa Desember 2019. Metode Penelitian ini menggunakan metode survei dengan pendekatan kuantitatif. Pengambilan sampel dilakukan di 10 stasiun menggunakan metode purposive sampling. Analisis data sistem karbonat menggunakan analisis komponen utama (PCA). Hasil dari penelitian ini menunjukkan bahwa kelimpahan fitoplankton tertinggi pada Perairan pantai Alang-alang Karimunjawa bulan Desember 2019 diperoleh pada ekosistem lamun dengan kisaran rata-rata sebesar 380 individu/L, sedangkan pada perairan lepas pantai hanya berkisar 200 individu/liter. Faktor-faktor yang paling mempengaruhi kelimpahan fitoplankton tersebut yaitu klorofil-a dengan nilai R2 sebesar 0,96 dan r sebesar 0,98, variabel lain yang memiliki hubungan kuat dengan kelimpahan fitoplankton berdasarkan analisis PCA (Principal Componen Analysis) yaitu nitrat dan silikat.
\end{abstract}

Kata kunci: Kelimpahan fitoplankton, lamun, Karimunjawa.

\section{ABSTRACT}

The purpose of this study was to determine the abundance of phytoplankton in seagrass ecosystems and offshore waters in Alang-alang Karimunjawa and its influencing factors. This research was conducted in Alang-alang Karimunjawa waters in December 2019. Method This study used a survey method with a quantitative approach. Sampling was conducted at 10 stations using purposive sampling method. Analysis of carbonate system data using principal component analysis (PCA). The results of this study indicate that the highest abundance of phytoplankton in the Alang-alang Karimunjawa coastal waters in December 2019 was obtained in seagrass ecosystems with an average range of 380 individuals / L, whereas in offshore waters only around 200 individuals / liter. The factors that most influence the abundance of phytoplankton are chlorophyll-a with R2 value of 0.96 and $r$ of 0.98 , other variables that have a strong relationship with phytoplankton abundance based on PCA (Principal Componen Analysis) analysis, namely nitrate and silicate.

Keywords: Abundance of phytoplankton, Seagrass, Karimunjawa.

Analisis Kelimpahan Fitoplankton di Perairan Alang-Alang Taman Nasional Karimunjawa - Nadhea Oktaviantina Rahmawati, Agus Hartoko \& Nurul Latifah 


\section{PENDAHULUAN}

Berdasarkan penelitian IPCC Pachauri (2014) Peningkatan konsentrasi gas rumah kaca di atmosfer disebabkan oleh peningkatan aktivitas manusia seperti penggunaan bahan bakar fosil untuk kepentingan industri dan transportasi, $\mathrm{AC}$, freon, kebakaran hutan dan sebagainya mengakibatkan peningkatan suhu permukaan rata-rata global yang diamati dari tahun 1951 hingga 2010. Peningkatan GRK di atmosfer, lautan dan daratan yang ada di bumi ini dapat menyebabkan pemanasan global/global warming.

Menurut Fourqurean et al., (2012) Gas $\mathrm{CO}_{2}$ ini memberikan kontribusi terbesar dalam pemanasan global, yaitu sebesar $50 \%$. Gas $\mathrm{CO}_{2}$ yang berada di atmosfer ini dapat berkurang jika penyerapan $\mathrm{CO}_{2}$ di laut tinggi. Penyerapan $\mathrm{CO}_{2}$ ini dilakukan oleh daratan melalui tanaman (vegetasi) dan lautan. Penyerapan $\mathrm{CO}_{2}$ ini terjadi melalui mekanisme proses fotosintesis yang dilakukan oleh tumbuhan hijau baik di darat maupun di laut. Penyerapan $\mathrm{CO}_{2}$ paling cepat dilakukan oleh oleh tanaman (vegetasi) di darat, akan tetapi penyimpanan yang lebih lama dilakukan oleh lautan. Menurut Cai \& Wang, (1998) lautan dapat menyerap dan menyimpan karbon lebih besar dan lama dibandingkan dengan daratan. Menurut Fourqurean et al., (2012) ekosistem padang lamun erat kaitannya dengan kehidupan fitoplankton dapat berkemampuan menyerap dan menyimpan $\mathrm{CO}_{2}$ dari atmosfir.

Menurut Hartati et al. (2017) Ekosistem lamun merupakan salah satu ekosistem penting di laut, disamping terumbu karang dan mangrove sebagai pendukung kehidupan biota. Ekosistem lamun memiliki fungsi ekologi diantaranya adalah sebagai habitat (tempat hidup), tempat pemijahan (spawning ground), tempat pengasuhan (nursery ground), tempat pembesaran (rearing ground) dan tempat mencari makanan (feeding ground) dari berbagai biota, selain itu juga sebagai produsen primer, penangkap sedimen, serta pendaur zat hara.

Menurut Fourqurean et al. (2012) ekosistem padang lamun erat kaitannya dengan kehidupan fitoplankton dapat berkemampuan menyerap dan menyimpan $\mathrm{CO}_{2}$ dari atmosfir. Ekosistem padang lamun dapat berkemampuan menyerap dan memindahkan jumlah besar karbon dari atmosfir setiap harinya, dan mengendapkannya dalam jaringan atau sedimen untuk waktu yang lama, sehingga keberadaan lamun di bumi sangat diperlukan sebagai jasa dalam penyerapan/ sekuestrasi karbon (Carbon Sequestration).
Menurut Firdaus \& Wijayanti (2019) Fitoplankton merupakan organisme planktonik (melayang-layang di air) yang mampu melakukan fotosintesis sebagaimana tumbuhan di darat. Selama fotosintesis, fitoplankton aktif menyerap karbon dari lingkungannya untuk membentuk senyawa karbohidrat sebagai sumber energi. Meskipun fitoplankton berukuran relatif kecil (mikroskopik), namun jumlah karbon bersih (netto) yang diserap oleh seluruh fitoplankton di laut hampir sama dengan jumlah karbon yang diserap oleh seluruh tumbuhan di darat. Artinya, hampir separuh dari jumlah penyerapan karbon dalam kegiatan fotosintesis secara global dilakukan oleh fitoplankton.

Meknisme fotosintesis oleh makhluk hidup di bumi ini erat kaitannya dengan siklus karbon. Siklus karbon adalah siklus biogeokimia yang mencangkup pertukaran/perpindahan karbon antara biosfer, pedosfer, geosfer, hidrosfer dan atmosfer bumi. Karbon yang ada di laut cenderung mengatur karbondioksida yang ada di atmosfer. Menurut Zeebe \& Gladrow (2003) Karbon anorganik yang berada di atmosfer diserap oleh laut kemudian $\mathrm{CO}_{2}$ di laut akan bereaksi dengan $\mathrm{H}_{2} \mathrm{O}$ membentuk reaksi kesetimbangan menjadi $\mathrm{H}_{2} \mathrm{CO}_{3}$ - dan membentuk reaksi kesetimbangan lagi bereaksi dengan ion $\mathrm{H}^{+}$menjadi $\mathrm{HCO}_{3}$. Karbon tersebut dimanfaatkan oleh organisme autotrof dalam proses fotosintesis untuk kelangsungan rantai makanan di laut. Karbon organik yang dihasilkan dari proses fotosintesis tersebut diubah menjadi karbon anorganik dan reaksi kesetimbangannya menjadi $\mathrm{H}^{+}+\mathrm{CO}_{3}{ }^{2-}$. Melalui proses kimiawi yang berlangsung lama $\mathrm{CO}_{2}$ yang terdekomposisi dari proses biologis makhluk hidup di laut tersebut dapat kembali lagi ke atmosfer melalui proses respirasi makhluk hidup (Takahashi et al., 2009) (Ikawa \& Oechel, 2011).

Karimunjawa adalah wilayah perairan tropis di Indonesia yang terletak di pulau Jawa Karimunjawa merupakan Taman Nasional yang difungsikan untuk menunjang konservasi alam, pariwisata, penelitian dan pendidikan. Padang lamun di Kepulauan Karimunjawa termasuk kedalam tiga ekosistem penting yang perlu dijaga kelestariannya. Menurut Ristina et al. (2018) bahwa Pantai Alang-alang merupakan pemukiman yang memiliki padang lamun yang kondisinya masih baik. Tujuan dilakukannya penelitian pada lokas ini yaitu Pantai Alang-alang memiliki ekosistem padang lamun yang cukup luas dan kondisinya tergolong baik dengan asosiasi biota yang cukup banyak, sehingga diharapkan penelitian ini dapat mengetahui kelimpahan fitoplankton dan faktor-faktor yang mempengaruhhi di perairan Alang-alang Karimunjawa. 


\section{BAHAN DAN METODE}

Penelitian ini dilakukan pada bulan Desember 2019 pada 10 stasiun pengamatan. Metode penelitian yang digunakan adalah metode survei dengan pendekatan kuantitatif, sedangkan metode yang digunakan untuk pengambilan sampel yaitu metode purposive sampling method atau pengambilan sampel dengan tujuan tertentu. Sampel diambil di 10 stasiun pengamatan yaitu stasiun 1-6 pada ekosistem lamun sedangkan stasiun 7-10 pada perairan lepas pantai Alang-alang Pulau Karimunjawa. Alasan penentuan stasiun pada ekosistem lamun dan perairan lepas pantai Alangalang ini dikarenakan lokasi tersebut dekat dengan spot wisata yang sering dikunjungi oleh wisatawan dengan keanekaragaman hayati yang cukup banyak. Penentuan stasiun pada ekosistem lamun diambil sebanyak 6 stasiun karena dianggap mewakili luas wilayah pengamatan pada ekosistem lamun perairan Alang-alang sedangkan pada perairan lepas pantai diambil sebanyak 4 stasiun menggunakan bentuk spasial yang dianggap mewakili wilayah pengamatan perairan pantai Alang-alang. Ekosistem lamun dan lepas pantai Alang-alang memiliki kondisi perairan yang cukup baik, sehingga pada ekosistem tersebut proses biologis dapat terjadi yaitu fotosintesis yang menyerap $\mathrm{CO}_{2}$ dan menghasilkan $\mathrm{O}_{2}$ serta terdapat biota dimana biota tersebut berkontribusi dalam proses respirasi yang mengeluarkan $\mathrm{CO}_{2}$. Menurut (Fourqurean et al., 2012) Ekosistem padang lamun mempunyai peranan penting dalam siklus karbon di laut karena menghasilkan produktivitas primer yang tinggi dan mampu menyimpan karbon dalam jumlah yang besar dalam waktu yang lama.

Variabel yang digunakan dalam penelitian ini antara lain $\mathrm{pH}$, salinitas, temperatur, $\mathrm{DO}, \mathrm{CO}_{2}$, klorofil-a, nitrat dan silikat. Pengambilan sampel air sebanyak $600 \mathrm{ml}$ pada ekosistem lepas pantai menggunakan alat Nansen Water Sampler pada kedalaman $\pm 1-3$ meter. Sedangkan pada ekosistem lamun pengambilan sampel air menggunakan botol sampel $600 \mathrm{ml}$ dan 1,5 liter untuk sampel klorofil-a dengan teknik sedemikian rupa supaya tidak terdapat gelembung. Sampel tersebut kemudian dimasukkan kedalam coolbox yang selalu diberi es batu. Sampel tersebut dianalisis di Laboratorium Pengelolaan Sumberdaya Ikan dan Lingkungan Depaartemen Sumberdaya Akuatik, FPIK Universitas Diponegoro.

\section{Pengukuran Nutrien Nitrat dan Silikat}

Menurut Risamasu et al. (2012) Metode pengukuran data zat hara pada umumnya menggunakan alat spektrofotometer yaitu dengan panjang $543 \mathrm{~nm}$ untuk pengukuran nitrat dan $810 \mathrm{~nm}$ untuk silikat.

\section{Pengukuran Klorofil-a \\ Klorofil-a}

Metode pengolahan data sampel klorofil-a dimulai dengan cara memasukkan sampel yang telah diekstaksi dengan asetton $90 \%$ kedalam tabung kaca yang dilapisi alumunium foile kemudian sampel di inkubasi kedalam lemari es selama 24 jam. Sampel tersebut kemudian dituang kedalam tabung centrifuge dan ditimbang dengan berat yang sama kemudian di sentrifuse.

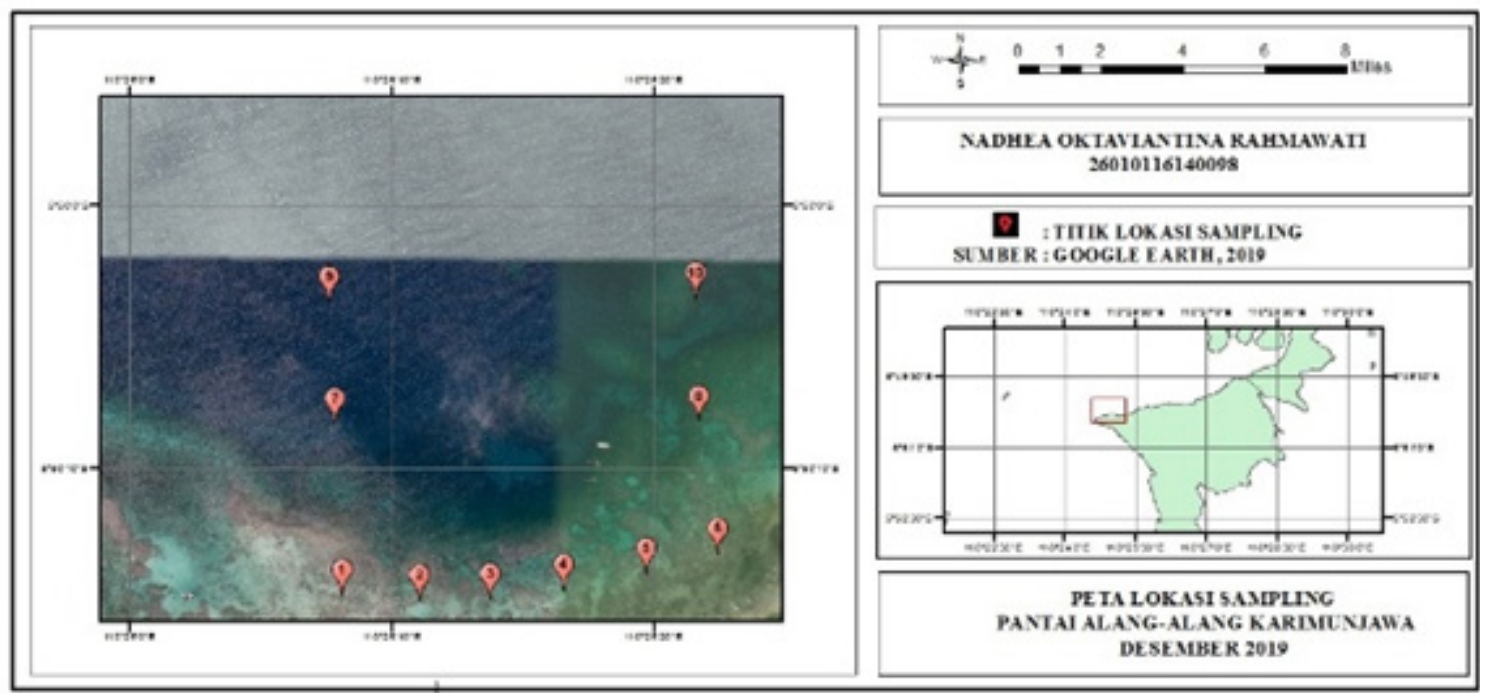

Gambar 1. Peta Lokasi Penelitian.

Figure 1. Research Site Map. 
Sampel yang telah di sentrifuse dituang kedalam cuvet dan dilihat nilai absorbansinya menggunakan alat spektrofotometer dengan panjang gelombang 664, 647 dan 630nm. Menurut Hidayah et al. (2016) Konsentrasi klorofil-a dihitung menggunakan rumus yaitu :

Chl- $a=11,85 \times \mathrm{A} 664-1,54 \times \mathrm{A} 647-0,08 \times \mathrm{A} 630$

Keterangan :

Chl-a : Kandungan klorofil-a $\left(\mathrm{mg} / \mathrm{m}^{3}\right)$

E : Penyerapan pada panjang gelombang yang bersangkutan.

Untuk menghitung kadar klorofil pada sampel air laut dalam satuan $\mathrm{mg} / \mathrm{m} 3$ maka nilai di atas dikalikan dengan factor (k) berdasarkan jumlah sampel air yang disaring.

$$
\mathrm{k}=\mathrm{Va} /(\mathrm{Vs} \times \mathrm{d})
$$

dimana, Va merupakan volume ekstrak (ml) ; Vs merupakan volume air laut yang disaring (liter) dan $\mathrm{d}$ merupakan lebar cuvet, path lengh $(\mathrm{cm})$.

\section{Fitoplankton}

Menurut Dewanti et al. (2018) Keanekaragaman fitoplankton dalam suatu perairan dapat diamati dibawah mikroskop dengan satuan individu/liter (ind/ liter). Metode pengamatan fitoplankton dilakukan dengan perbesaran $10 \times 10$ sebanyak 3 kali pengulangan. Identifikasi fitoplankton berpedoman pada buku Yamaji (1986). Perhitungan kelimpahan fitoplankton dapat dihitung menggunakan rumus (APHA, 1989) yaitu :

\section{$\mathrm{N}=\mathrm{ZX} / \mathrm{Y} \times \mathrm{L} / \mathrm{V}$}

Keterangan :

$\mathrm{N} \quad$ : Kelimpahan individu (ind/liter)

Z : Jumlah individu fitoplankton

$\mathrm{X} \quad$ : Volume air sampel yang tersaring $(50 \mathrm{ml})$

Y : Volume dalam Sedgwick rafter counting cell

$(\mathrm{ml})$

V : Volume air yang tersaring $(100 \mathrm{~L})$

L : : Luas lapang pandang pada microskop $\left(0,25 \Omega \mathrm{mm}^{2}\right)$

\section{Analisis Komponen Utama (Principal Component Analysis)}

Menurut Dewanti et al. (2018) Analisi PCA atau Principal Component Analisys disebut juga sebagai analisis komponen utama merupakan metode statistic deskriptif yang bertujuan untuk menyajikan informasi maksimum yang terdapat dalam suatu matriks data kedalam bentuuk grafik. Menurut Erlania et al., (2013) Hasil analisis PCA dapat menunjukkan korelasi antar parameter pada setiap stasiun selain itu anaisis PCA juga dapat mengelompokkan kemiripan dari parameter lingkungan yang berbentuk matriks data.

Parameter fisika-kimia oseanografi dan sistem $\mathrm{CO} 2$ yang dominan terhadap perubahan nilai tekanan parsial dan fluks $\mathrm{CO}_{2}$ dapat ditentukan dengan analisis PCA (Principal Component Analysisis). Dimana hasil dari analisis PCA ini dapat menunjukkan parameter-parameter atau variabel penelitian yang berperan penting. Analysisis PCA dilakukan dengan menggunakan data yang sudah distandardisasi per

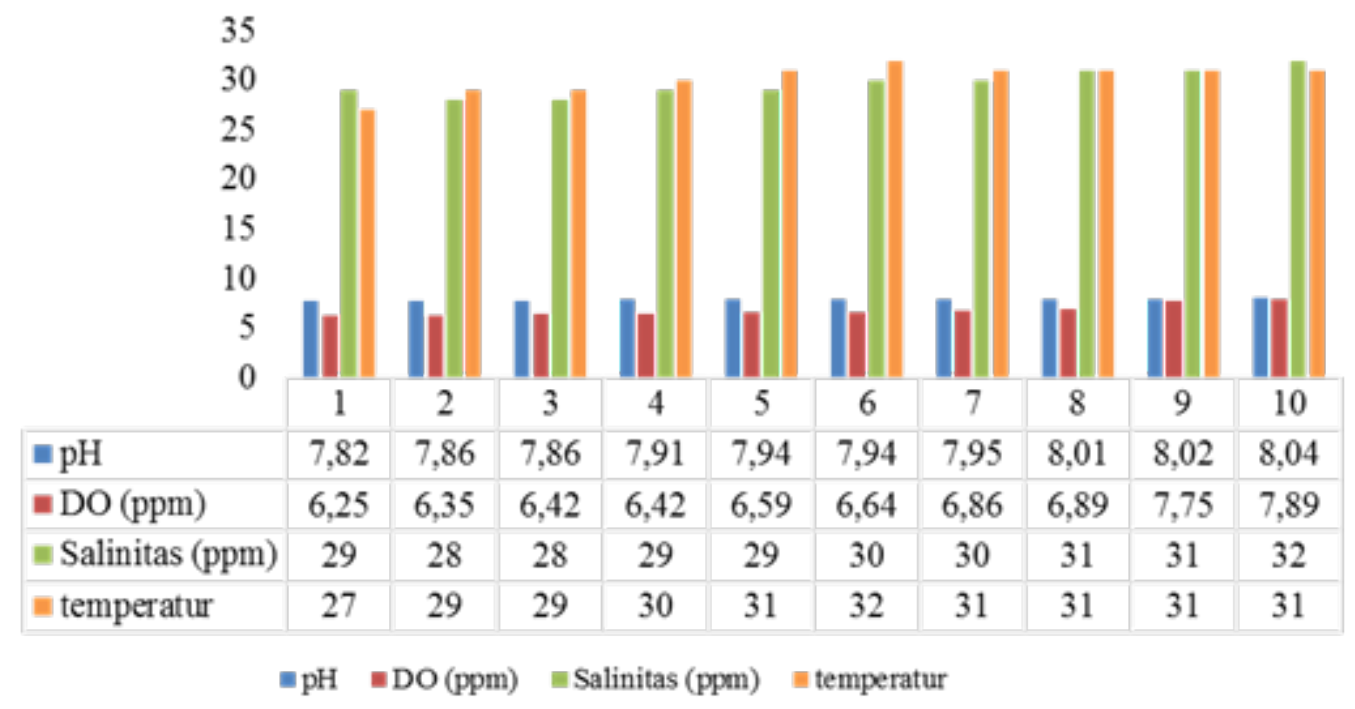

Gambar 2. Hasil Pengukuran Kualitas Air Perairan Alang-Alang Karimunjawa.

Figure 2. Results of Water Quality Measurement of Alang-Alang Karimunjawa Waters. 
variabel terhadap total masing-masing variabel Afdal (2016); Zulhaniarta et al., (2015)

\section{Analisis Regresi Polinomial}

Analisis regresi polinomial memiliki persamaan $y=a 2$ $\mathrm{x}^{2}+\mathrm{a} 1 \mathrm{x}+\mathrm{a}$ dengan $\mathrm{y}$ merupakan variabel respon, $\mathrm{a}$ merupakan intersep, a1 dan a2 merupakan koefisien regresi dan x merupakan variabel prediktor. Setelah itu dilakukan analisis data regresi berganda menggunakan software IBM SPSS 26 untuk mengetahui hubungan antara keempat variabel (Kerapatan lamun terhadap kelimpahan fitoplankton) tersebut. Analisis regresi berganda memiliki persamaan $\mathrm{y}=\mathrm{a}+\mathrm{bx} 1+\mathrm{bx} 2+$ bx3 dimana y yaitu koefisien dependen (kelimpahan fitoplankton). Analisis tersebut digunakan untuk menentukan koefisien korelasi dimana nilai koefisien korelasi menunjukan kuat atau tidaknya hubungan antar dua variabel. Koefisien korelasi dilambangkan dengan huruf $\mathrm{R}$ serta bernilai dari -1 sampai +1 . Apabila bernilai negative maka artinya kedua variabel tersebut bernilai berlawanan. Koefisien determinasi atau R2 untuk menentukan seberapa jauh hubungan antara variable

\section{HASIL DAN PEMBAHASAN}

\section{Hasil}

\section{Kualitas Air Perairan}

Hasil pengukuran variabel fisika dan kimia perairan yang diperoleh pada masing-masing stasiun pengamatan disajikan pada gambar 3. Berdasarkan data pengukuran variabel fisika-kimia perairan Pantai Alang-alang Karimunjawa yang diperoleh dengan waktu yang sama pada pengambilan sampel setiap parameter yaitu pada saat surut sekitar pukul 08.00-14.00 WIB dimana pada sekitar lokasi tersebut tidak ditemukan muara sungai, nilai $\mathrm{pH}$ pada ekosistem lamun (stasiun 1-6) berkisar antara 7,82-7,94, sedangkan nilai $\mathrm{pH}$ pada perairan lepas pantai (stasiun 7-10) berkisar antara 7,95-8,04 Nilai $\mathrm{pH}$ tertinggi pada stasiun 6 dan nilai terendah pada stasiun 1. Nilai $\mathrm{pH}$ tertinggi pada ekosistem leppas pantai yaitu stasiun 10 dan terendah pada stasiun 7 . Kandungan Dissolved Oxygen pada ekosistem lamun berkisar antara 6,25-6,64 ppm dengan nilai tertinggi pada stasiun 6 dan terendah pada stasiun 1, sedangkan nilai Dissolved Oxygen pada perairan lepas pantai berkisar antara 6,86-7,89 ppm, dengan nilai tertinggi pada stasiun 10 dan nilai terendah terdapat pada stasiun 7. Salinitas pada ekosistem lamun yang didapatkan cukup fluktuatif yaitu berkisar antara 28-30 ppm, nilai tertinggi diperoleh pada stsiun 6 dan terendah pada stasiun 2-3. Sedangkan pada perairan lepas pantai nilai salinitas berkisar antara 30-32 ppm, nilai tertinggi diperoleh pada stsiun 10 dan terendah pada stasiun 7 . Nilai temperatur yang diperoleh juga cukup fluktuatif yaitu pada ekosistem lamun berkisar antara 27-32oC, nilai tertinggi diperoleh pada stasiun 6 dan terendah pada stasiun 1, sedangkan pada perairan lepas pantai nilai temperatur berkisar antara 30-31, nilai tertinggi pada stasiun 7 .

\section{Klorofil-a dan nutrien Perairan Hasil pengukuran klorofil-a, nitrat dan silikat}

perairan yang diperoleh pada masing-masing stasiun pengamatan tersaji dalam bentuk grafik. Berdasarkan data pengukuran klorofil-a, nitrat dan silikat pada perairan Pantai Alang-alang diperoleh kisaran nilai klorofil-a pada ekosistem lamun yaitu sebesar 0,389. $0,480 \mathrm{mg} / \mathrm{m} 3$. Konsentrasi klorofil-a tertinggi diperoleh pada stasiun 1 dan terendah pada stasiun 6 . Sedangkan pada perairan lepas pantai yaitu sebesar 0,389-0,423 $\mathrm{mg} / \mathrm{m} 3$, dimana nilai tertinggi diperoleh pada stasiun 7 dan terendah pada stasiun 10 . Konsentrasi nirat pada ekosistem lamun berkisar antara 0,210-1,245 N-NO3 $\mathrm{mg} / \mathrm{L}$, nilai tertinggi diperoleh pada stasiun 3 dan terendah pada stasiun 2 .

Perairan lepas pantai berkisar antara 0,279-1,417 $\mathrm{N}-\mathrm{NO} 3 \mathrm{mg} / \mathrm{L}$, nilai tertinggi diperoleh pada stasiun 7 dan terendah pada stasiun 10. Konsentrasi silikat yang diperoleh pada ekosistem lamun berkisar antara 0,0380,131 $\mathrm{Si}-\mathrm{SiO} 2 \mathrm{mg} / \mathrm{L}$, dimana nilai tertinggi diperoleh pada stasiun 3 dan terendah pada stasiun 5. Sedangkan pada perairan lepas pantai berkisar antara 0,038-0,090 $\mathrm{Si}-\mathrm{SiO} 2 \mathrm{mg} / \mathrm{L}$, dimana nilai tertinggi diperoleh pada stasiun 10 dan terendah pada stasiun 9.

\section{Kelimpahan Fitoplankton}

Berdasarkan hasil pengamatan dan perhitungan kelimpahan fitoplankton pada ekosistem lamun (stasiun 1-6) pantai Alang-alang Karimunjawa berkisar antara 300-473 individu/liter dimana nilai kelimpahan tertinggi yaitu pada stasiun 1 dan terendah pada stasiun 6. Sedangkan pada periran lepas pantai (stasiun 7-10) berkisar antara 153-247 individu/liter dimana nilai kelimpahan tertinggi yaitu pada stasiun 7 dan terendah pada stasiun 10 .

\section{Analisi PCA (Principal Component Analysis)}

Hasil analisis PCA Kelimpahan Fitoplankton di perairan pantai Alang-alang Karimunjawa menggunakan software minitab 19. Berdasarkan hasil analisis PCA dapat diketahui bahwa ketiga komponen utama yaitu PC1, PC 2 dan PC 3 memiliki eigentvalue $>1$ yaitu sebesar 5,049, proporsi sebesar 63\%, 16,3\% dan 1,03\% dan memiliki nilai comulative secara berturut-turut 
sebesar $63 \%, 79,4 \%$ dan $89,7 \%$. Komponen utama atau dependeen variabel (vriabel yang dipengaruhi) yaitu nitrat, silikat, DO, dan temperatur, sedangkan komponen kedua atau independeen variabel (variabel yang mempengaruhi) yaitu klorofil-a, kelimpahan fitoplankton, salinitas dan $\mathrm{pH}$ (Gambar 7).

\section{Pembahasan}

\section{Kualitas Air}

Menurut Cox et al. (2012) Salinitas memiliki kaitan erat dengan $\mathrm{pH}$ sehingga merupakan faktor penting yang mempengaruhi kelarutan $\mathrm{CO}_{2}$ dalam air laut. Menurut Afdal (2016) Semakin tinggi nilai salinitas akan menyebabkan kelarutan $\mathrm{CO}_{2}$ semakin tinggi. $\mathrm{CO}_{2}$ terlarut tersebut akan bereaksi dengan kalsium membentuk $\mathrm{CaCO}_{3}$. Kelarutan $\mathrm{CO}_{2}$ dalam air laut ini disebut DIC (Dissolved Inorganic Carbon). Hal ini dapat dilihat pada gambar 3 bahwa tingginya nilai $\mathrm{pH}$ dan salinitas pada stasiun 10 diikuti dengan tingginya nilai DIC. DIC didalam air laut terdiri dari bikarbonat $\left(\mathrm{HCO}_{3}-\right)$, karbonat $\left(\mathrm{CO}_{3}{ }^{2}\right)$ dan $\mathrm{CO}_{2}$ bebas terlarut.

Kadar $\mathrm{CO}_{2}$ bebas ini juga berkaitan erat dengan $\mathrm{pH}$, dimana apabila nilai $\mathrm{pH}$ di perairan semakin tinggi dapat menurunkan kadar $\mathrm{CO}_{2}$ bebas (gambar 3). Hal ini dikarenakan kadar karbondioksida merupakan hasil dari proses respirasi makhluk hidup di perairan. Menurut Prasetyawan et al. (2017) Terlepasnya karbondioksida dapat bereaksi dengan air dan membentuk asam karbonat yang kemudian direduksi menjadi bikarbonat dan karbonat sehingga dapat menjadikan $\mathrm{pH}$ semakin rendah Selain itu, tingginya temperature juga dapat

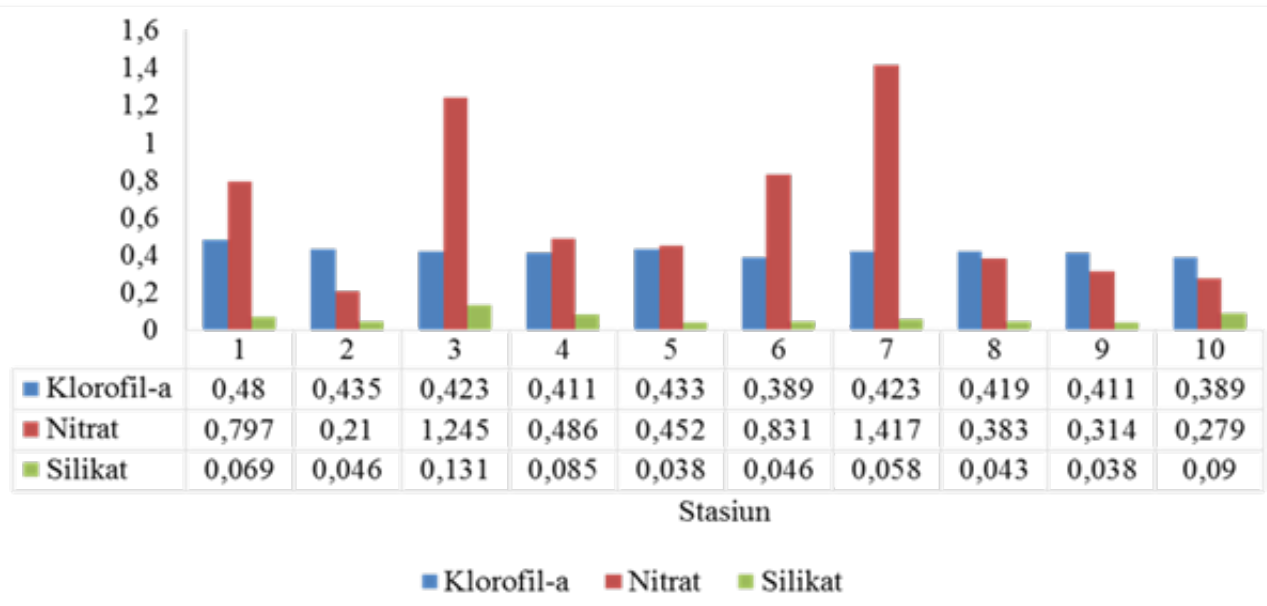

Gambar 3. Hasil Pengukuran Klorofil-a dan Nutrien di perairan Alang-alang Karimunjawa.

Figure 3. Results of Measurement of Chlorophyll-a and Nutrients in Alang-alang Karimunjawa waters.

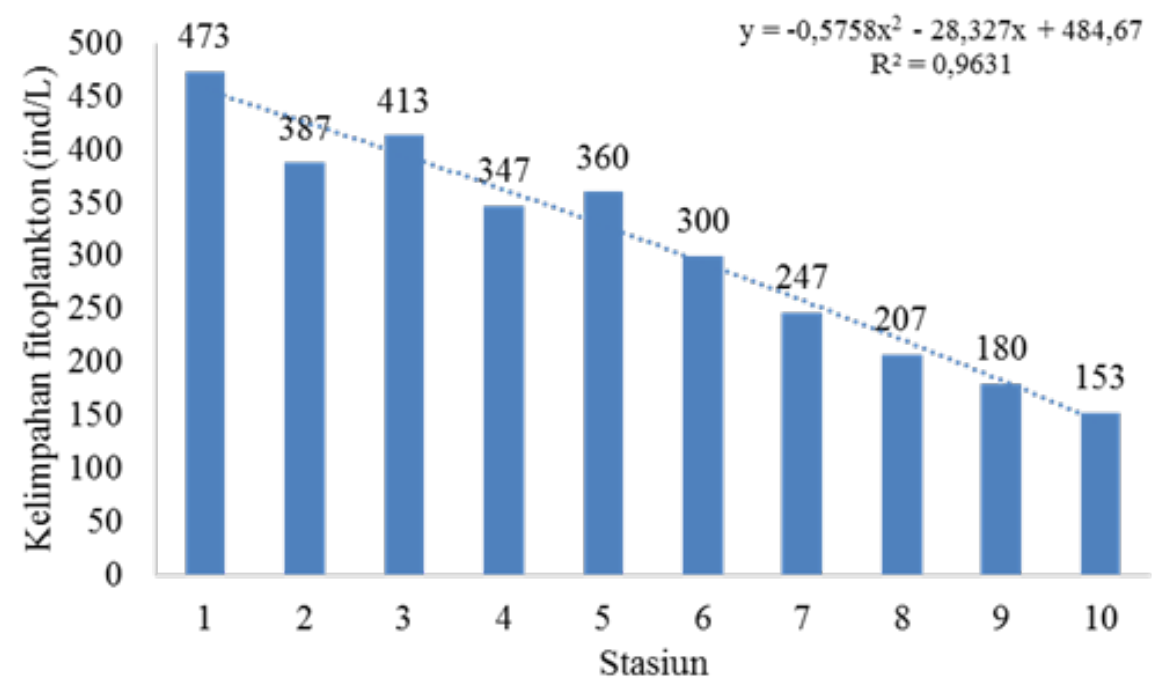

Gambar 4. Hasil Kelimpahan Fitoplankton perairan Alang-alang Karimunjawa. Figure 4. Results of Phytoplankton Abundance in Karimunjawa Alang Alang. 
Eigenvalue $5,0498 \quad 1,30240,82770,59830,10750,06880,04440,0010$

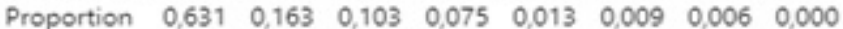

Cumulative $\begin{array}{llllllll}0,631 & 0,794 & 0,897 & 0,972 & 0,986 & 0,994 & 1,000 & 1,000\end{array}$

Gambar 5. Hasil Analisis PCA (Principal Component Analysis).

Figure 5. Results of PCA (Principal Component Analysis) Analysis.

menyebabkan semakin meningkatnya nilai salinitas. Hal ini terlihat pada gambar 3 tingginya temperature pada stasiun $7-10$ sebesar $30-31^{\circ} \mathrm{C}$ diikuti dengan tingginya nilai salinitas sebesar 30-32 ppm. Penelitian ini dilakukan pada saat peralihan musim Timur ke Barat, yaitu saat kondisi pantai surut dan tidak terjadi hujan, namun saat malam hari hingga dini hari kondisi cuaca pada lokai sekitar pengamatan terjadi hujan angin. Menurut Rustam et al. (2014) Pada saat terjadi hujan menyebabkan salinitas menjadi rendah dikarenakan mendapatkan masukan air tawar dan input sungai, sebaliknya saat musim kemarau dengan suhu tinggi salinitas meningkat.

\section{Klorofil-a dan nutrient Perairan}

Ekosistem padang lamun merupakan ekosistem yang cukup kompleks dengan segala fungsi yang penting terhadap ekosistem pesisir. Ekosistem lamun memiliki keterkaitan dengan ekosistem di wilayah pesisir seperti mangrove, terumbu karang, estauria dan ekosistem lainya dalam menunjang keberadaan biota terutama dalam aspek perikanan. Selain aspek tersebut, beberapa aspek lain seperti fungsi fisik dan sosial-ekonomi juga dipengaruhi oleh ekosistem pesisir. Menurut Tangke (2010) Hal ini menunjukkan bahwa ekosistem lamun tidak dapat berdiri sendiri, tetapi terkait dengan ekosistem sekitarnya. Salah satu proses kehidupan tanaman yaitu fotosintesis yang merupakan proses biokimia untuk memproduksi energi terpakai (nutrisi), dimana karbon dioksida $\left(\mathrm{CO}_{2}\right)$ dan air $\left(\mathrm{H}_{2} \mathrm{O}\right)$ dibawah pengaruh cahaya diubah ke dalam persenyawaan organik yang berisi karbon. Fotosintesis merupakan salah satu cara asimilasi karbon karena dalam fotosintesis karbon bebas dari $\mathrm{CO}_{2}$ diikat (difiksasi) menjadi gula sebagai molekul penyimpan energi. Reaksi dalam fotosintesis yang menghasilkan glukosa ialah sebagai berikut: $6 \mathrm{H}_{2} \mathrm{O}+6 \mathrm{CO}_{2}+$ cahaya $\rightarrow \mathrm{C}_{6} \mathrm{H}_{12} \mathrm{O}_{6}$ (glukosa) $+6 \mathrm{O}_{2}$, (Pertamawati, 2010).

Pada lokasi pengamatan ditemukan terumbu karang dengan kondisi yang tergolong cukup baik. Menurut Kawaroe (2009) Salah satu sumberdaya laut yang cukup potensial sebagai penyimpan gas $\mathrm{CO}_{2}$ adalah padang lamun. Menurut Kaswadji \& Koorpotan (2012) Fungsi dari lamun yaitu sebagai penyimpan karbon di lautan (carbon sink) atau dikenal dengan istilah blue carbon dan digunakan untuk proses fotosintesis. Menurut Latifah et al. (2019) Ekosistem terumbu karang yaitu ekosistem dengan tingkat produktivitas primer yang tinggi. Produktivitas primer ini merupakan masukan dari daratan berupa nutrient organik yang akan memicu pertumbuhan fitoplankton terutama di daerah pesisir. Hal ini dapat dilihat pada gambar 6 bahwa rata-rata nilai klorofil-a pada ekosistem lamun lebih tinggi sebesar

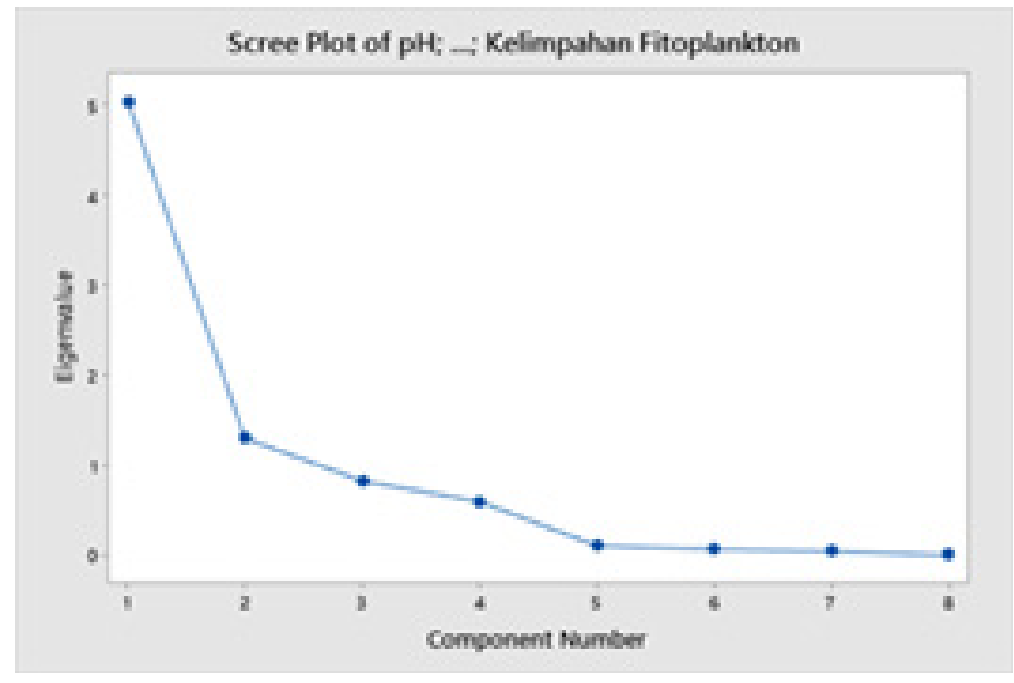

Gambar 6. Eigenvalue Hasil Analisis PCA (Principal Component Analysis). Figure 6. Eigenvalue Results of PCA Analysis (Principal Component Analysis)s. 


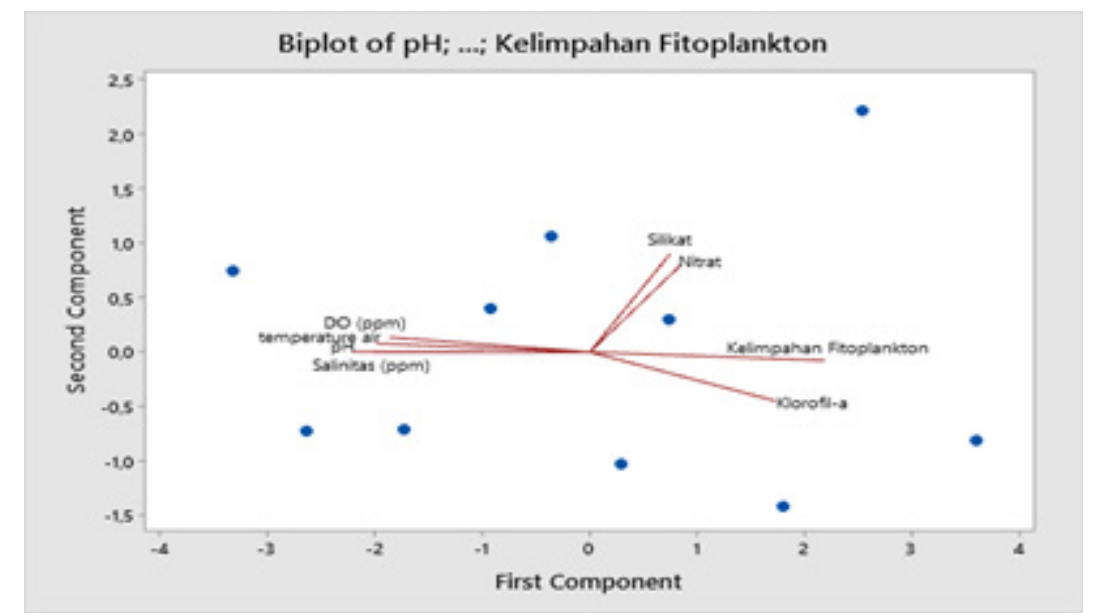

Gambar 7. Grafik Biplot Hasil Analisis PCA (Principal Component Analysis).

Figure 7. Biplot Graph of PCA Analysis (Principal Component Analysis).

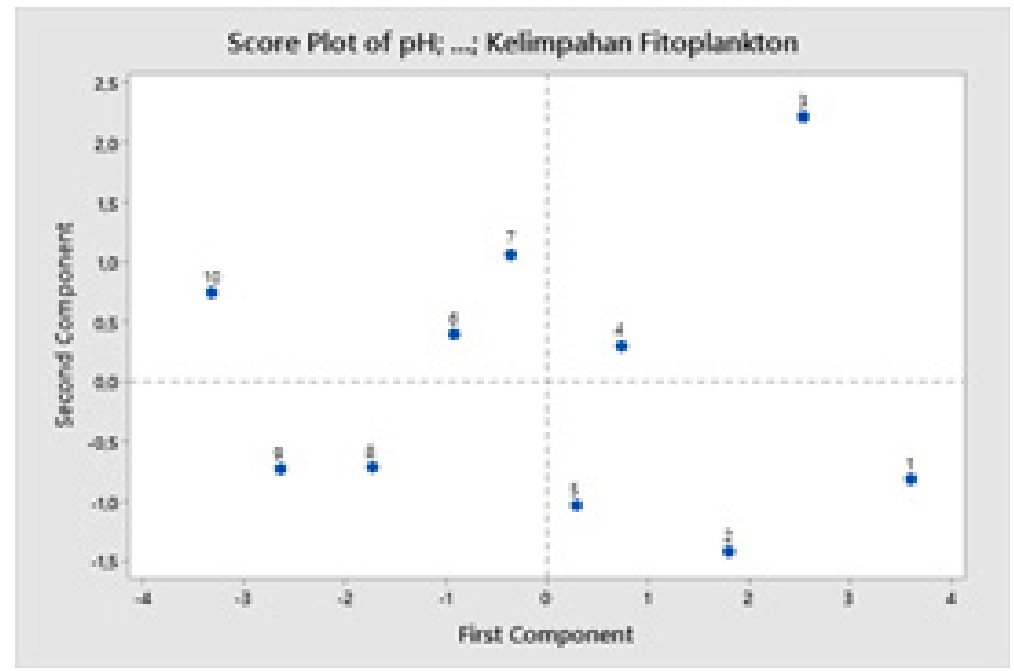

Gambar 8. Grafik Score Plot Hasil Analisis PCA (Principal Component Analysis).

Figure 8. Score Plot Graph of PCA Analysis (Principal Component Analysis).

$0,428 \mathrm{mg} / \mathrm{m}^{3}$ dibandingkan dengan perairan lepas pantai yaitu sebesar $0,401 \mathrm{mg} / \mathrm{m}^{3}$, begitupula dengan nilai nitrat pada ekosistem lamun lebih tinggi sebesar $0,670 \mathrm{~N}-\mathrm{NO}_{3} \mathrm{mg} / \mathrm{L}$ dibandingkan dengan perairan lepas pantai yaitu sebesar $0,598 \mathrm{~N}-\mathrm{NO}_{3} \mathrm{mg} / \mathrm{L}$. Menurut Hartoko \& Kangkan (2010) kisaran nilai nutrien di perairan Kupang yang memiliki kondisi hampir sama dengan lokasi pengamatan cenderung tinggi sehingga mendukung pertumbuhan fitoplankton. Tingginya nutrien di perairan tersebut dapat meningkatkan konsumsi karbon anorganik terlarut oleh fitoplankton sehingga dapat merubah kesetimbangan tekanan parsial $\mathrm{CO}_{2}\left(\mathrm{pCO}_{2}\right)$ permukaan air.

\section{Kelimpahan Fitoplankton}

Berdasrkan hasil kelimpahan fitoplankton dan kerapatan lamun (gambar 7, 8 dan 9) dapat dilihat bahwa kelimpahan fitoplankton tertinggi terdapat pada ekosistem lamun (stasiun 1-6) dengan nilai ratarata 380 individu/liter yang diikuti dengan tingginya kerpatan lamun, sedangkan pada perairan lepas pantai hanya berkisar antara 200 individu/liter. Kelimpahan fitoplankton dengan jnis lamun yang terdapat di lokasi peneitian memiliki hungan yang linear. Menurut Hartati et al. (2017) jenis lamun yang memiliki morfologi berukuran besar cenderung memiliki biomassa karbon yang tinggi pula. Jenis lamun Enhalus accoroides memiliki morfologi paling besar diantara jenis lamun yang lainnya sehingga Enhalus accoroides menjadi penyumbang biomassa terbesar. Nilai kerapatan dan presentase tutupan lamun juga mempengaruhi biomassa karbon lamun. 


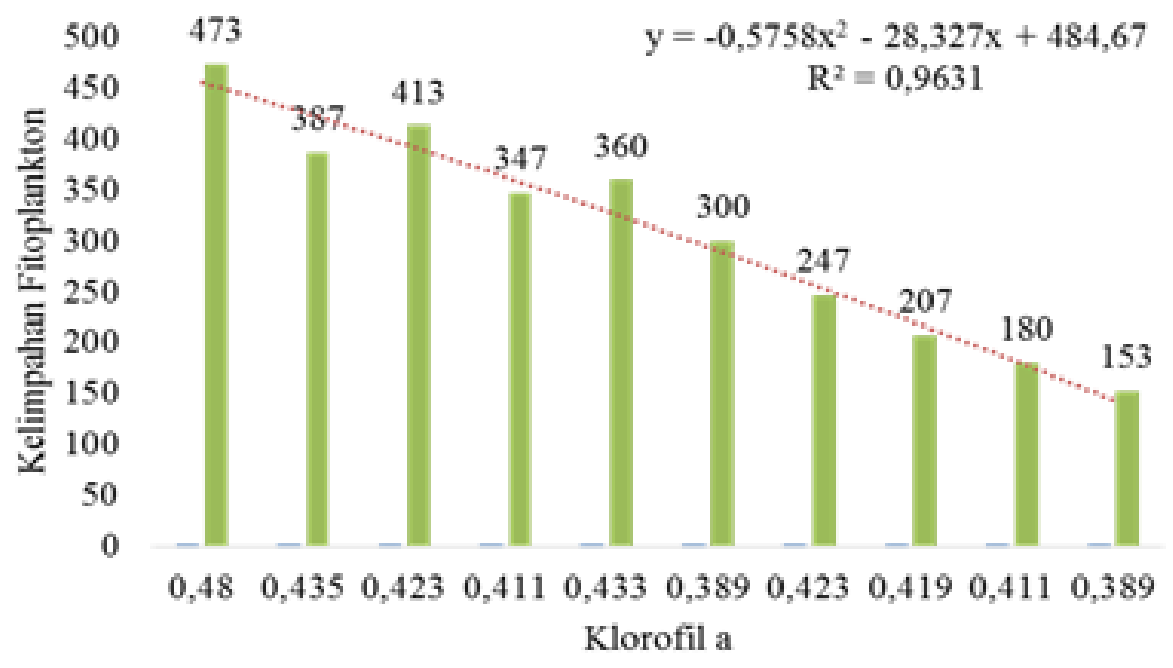

Gambar 9. Analisis Regresi Polinomial Klorofil-a dan kelimpahan fitoplankton.

Figure 9. Analysis of Chlorophyll-a Polynomial Regression and abundance of phytoplankton.

\section{Analisis Data}

Berdasarkan hasil analisis PCA (gambar 5,6,7 dan 8) dapat diketahui bahwa ketiga komponen utama yaitu PC1, PC 2 dan PC 3 memiliki ragam sama dengan eigentvalue $>1$ mewakili $90 \%$ dari keragaman total. Menurut Erlania et al. (2013) Hasil analisis komponen utama (PCA) mengekstrak dua komponen utama pertama yang memiliki eigenvalue lebih besar dari satu dan memiliki nilai ragam kumulatif lebih dari $70 \%$.

\section{PCA (Principal Component Analysis)}

Hal ini menunjukkan bahwa 3 komponen utama tersebut cukup menjelaskan ragam/ variasi dalam data yang menunjukkan bahwa korelasi anatara beberapa variabel dan kelayakan analisis PCA tersebut adalah valid. Grafik score plot (gambar 8) dapat menjelaskan persebaran variabel pada masing-masing stasiun yang terdapat pada grafik biplot (gambar 7). Berdasarkan grafik tersebut dapat diketahui bahwa pada stasiun 1,2 dan 5 variabel yang mendominasi yaitu klorofil a dan kelimpahan fitoplankton, hal ini terlihat pada gambar (2 dan 4) nilai tertinggi kedua variabel tersebut tedapat pada stasiun 1.

Variabel yang mendominasi pada stasiun 3 dan 4 yaitu nitrat dan silikat, hal ini juga terlihat pada (gambar 3) bahwa nilai tertnggi kedua variabel tersebut terdapat pada stasiun 3. Variabel yang mendominasi pada stassiun 8 dan 9 yaitu $\mathrm{pH}$ dan Salinitas sedangkan variabel yang mempengaruhi stasiun 6,7 dan 10 yaitu DO dan temperatur (gambar 2 dan 6).

Berdasarkan grafik biplot (gambar 8) dapat diketahui bawa kelimpahan fitoplankton memiliki hubungan kuat dengan klorofil-a dan keduanya merupakan variabel yang saling mempengaruhi. Hal ini juga diperkuat dengan analisis regresi polinomial antara klorofil-a dan kelimpahan fitoplankton yang memiliki nilai R2 sebesar 0,96 dan $r$ sebesar 0,98 (gambar 9). Hasil nilai korelasi dari analisis regresi polinomial klorofil-a dan kelimpahan fitoplankton menunjukan korelasi kuat dengan nilai positif antara variabel klorofil-a terhadap kelimpahan fitoplankton dimana nilai korelasinya mendekati 1. Hal ini menunjukkan bahwa klorofil-a mempengaruhi pertumbuhan fitoplankton pada suatu perairan yang dimanfaatkan dalam proses fotosintesis. Menurut Agustin et al. (2014) bahwa kemampuan lamun dalam berfotosintesis memanfaatkan $\mathrm{CO}_{2}$ dan menyimpannya dalam biomassa atau dikenal dengan istilah blue carbon. Menurut Fourqurean et al., (2012) ekosistem padang lamun erat kaitannya dengan kehidupan fitoplankton dapat berkemampuan menyerap dan menyimpan $\mathrm{CO}_{2}$ dari atmosfir.

\section{KESIMPULAN DAN SARAN}

Kelimpahan fitoplankton tertinggi pada Perairan pantai Alang-alang Karimunjawa Desember 2019 diperoleh pada ekosistem lamun dengan kisaran rata-rata sebesar 380 individu/L, sedangkan pada perairan lepas pantai hanya berkisar 200 individu/liter. Faktor-faktor yang paling mempengaruhi kelimpahan fitoplankton tersebut yaitu klorofil-a dengan nilai R2 sebesar 0,96 dan $r$ sebesar 0,98, variabel lain yang memiliki hubungan kuat dengan kelimpahan fitoplankton berdasarkan analisis PCA (Principal Componen Analysis) yaitu nitrat dan silikat. 


\section{UCAPAN TERIMA KASIH}

Penulis mengucapkan terima kasih kepada Pemberi dana penelitian yaitu Lembaga Penelitian dan Pengabdian Masyarakat (LPPM) Universitas Diponegoro, sumber dana selain APBN DPA LPPM Universitas Diponegoro Tahun 2019 dengan Nomor SPK 385-31/UN7.P4.3/PP/2019.

\section{DAFTAR PUSTAKA}

Afdal. (2016). Fluks $\mathrm{CO}_{2}$ di Perairan Pesisir Pulau Lombok, Nusa Tenggara Barat. Oseanologi Dan Limnologi, 1(2), 91-103. 10.14203/oldi.2016. v1i2.14

Agustin, R., Kepel, T. L., Afiati, R. N., Salim, H. L., Astrid, M., Daulat, A., Mangindaan, P., Sudirman, N., Rahayu, Y. P., Suryono, D. D., \& Hutahaenan, A. (2014). Peran Ekosistem Lamun Sebagai Blue carbon Dalam Mitigasi Perubahan Iklim, Studi Kasus Tanjung Lesung, Banten. Jurnal Segara, 10(2), 107-117.

Cai, W. J., \& Wang, Y. (1998). The chemistry, fluxes, and sources of carbon dioxide in the estuarine waters of the Satilla and Altamaha Rivers, Georgia. Limnology and Oceanography, 43(4), 657-668.

Cox, E. J., Marxsen, J., \& Horvath, T. G. (2012). Primary Producers. Central European Stream Ecosystems: The Long Term Study of the Breitenbach, III(2), 99-129.

Dewanti, L. P. P., Putra, I. D. N. N., \& Faiqoh, E. (2018). Hubungan Kelimpahan dan Keanekaragaman Fitoplankton dengan Kelimpahan dan Keanekaragaman Zooplankton di Perairan Pulau Serangan, Bali. Journal of Marine and Aquatic Sciences, 4(2), 324-335.

Erlania, E., Nirmala, K., \& Soelistyowati, D. T. (2013). Penyerapan Karbon pada Budidaya Rumput Laut Kappaphycus alvarezii dan Gracilaria gigas diPerairan Teluk Gerupuk, Lombok Tengah, Nusa Tenggara Barat. Jurnal Riset Akuakultur, 8(2), 287-297.

Firdaus, M. R., \& Wijayanti, L. A. S. (2019). Fitoplankton dan Siklus Karbon Global. Oseana, 44(2), 35-48.
Fourqurean, J. W., Duarte, C. M., Kennedy, H., Marbà, N., Holmer, M., Mateo, M. A., Apostolaki, E. T., Kendrick, G. A., Krause-Jensen, D., McGlathery, K. J., \& Serrano, O. (2012). Seagrass ecosystems as a globally significant carbon stock. Nature Geoscience, 5(7).

Hartati, R., Pratikto, I., \& Pratiwi, T. N. (2017). Biomassa dan Estimasi Simpanan Karbon pada Ekosistem Padang Lamun di Pulau Menjangan Kecil dan Pulau Sintok, Kepulauan Karimunjawa. Buletin Oseanografi Marina, 6(1), 74-81.

Hartoko, A., \& Kangkan, A. L. (2010). Spatial Modeling for Mariculture Site Selection Based on Ecosystem Parameters At Kupang Bay, East Nusa Tenggara Indonesia. International Journal of Remote Sensing and Earth Sciences (IJReSES), 6(1), 57-64.

Hidayah, G., Wulandari, S. Y., \& Zainuri, M. (2016). Studi Sebaran Klorofil-a Secara Horizontal di Perairan Muara Sungai Silugonggo Kecamatan Batangan, Pati. Buletin Oseanografi Marina, $5(1), 52-59$.

Ikawa, H., \& Oechel, W. C. (2011). Air-sea $\mathrm{CO}_{2}$ exchange of beach and near-coastal waters of the Chukchi Sea near Barrow, Alaska. Continental Shelf Research, 31(13), 1357-1364.

Kaswadji, R. F., \& Koropitan, A. F. (2012). Pertukaran Gas CO2 Udara-Laut di Perairan Selat Nasik, Belitung. Jurnal Perairan Tropis, 1(2),43.

Kawaroe, I. M. (2009). Perspektif lamun sebagai blue carbon sink di laut. 2, 1-12.

Latifah, N., Endrawati, H., \& Febrianto, S. (2019). Distribusi Spasial Fluks Karbon Dioksida Di Perairan Karimunjawa, Indonesia. Jurnal Ilmu Dan Teknologi Kelautan Tropis, 11(2), 357-368. https://doi.org/10.29244/jitkt.v11i2.23692

Pertamawati. (2010). Pertumbuhan Tanaman Kentang (Solanum Tuberosum L) Dalam Lingkungan Fotoautotrof Secara Invitro. Sains Dan Teknologi Indonesia, 12(1), 31-37.

Prasetyawan, I. B., Maslukah, L., \& Rifai, A. (2017). 
Pengukuran Sistem Karbon Dioksida $\left(\mathrm{CO}_{2}\right)$ Sebagai Data Dasar Penentuan Fluks Karbon Di Perairan Jepara. Buletin Oseanografi Marina, 6(1), 9-16.

Pachauri, R. K., L. A. M. \& C. W. T. (2014). Climate Change 2014 Synthesis Report Summary Chapter for Policymakers. Ipcc, 151. https://doi. org/10.1017/CBO9781107415324

Risamasu, F. J. L., Prayitno, B., Pembahasan, H., \& Metode, M. (2012). Kajian Zat Hara Fosfat, Nitrit, Nitrat dan Silikat di Perairan Kepulauan Matasiri, Kalimantan Selatan. Ilmu Kelautan Indonesian Journal of Marine Sciences, 16(3), 135-142.

Ristina, M., Sulardiono, B., \& Solichin, A. (2018). Hubungan Kerapatan Lamun (Seagrass) dengan Kelimpahan Teripang (Holothuria) di Pantai Alang-Alang Taman Nasional Karimunjawa. Journal of Maquares, 7(4), 452-457.

Rustam, A., Bengen, D. G., Gaol, Z. A. \& J. L. (2014). Dissolved inorganic carbon (DIC). Aquatic Ecology, 6(Dic), 397-415.

Takahashi, T., Sutherland, S. C., Wanninkhof, R., Sweeney, C., Feely, R. A., Chipman, D. W., Hales, B., Friederich, G., Chavez, F., Sabine, C., Watson, A., Bakker, D. C. E., Schuster, U., Metzl, N., Yoshikawa-Inoue, H., Ishii, M., Midorikawa, T., Nojiri, Y., Körtzinger, A., ... de Baar, H. J. W. (2009). Climatological mean and decadal change in surface ocean pCO2, and net sea-air $\mathrm{CO} 2$ flux over the global oceans. Deep-Sea Research Part II: Topical Studies in Oceanography, 56(8-10), 554-577.

Tangke, U. (2010). Ekosistem Padang Lamun. Jurnal Ilmiah Agribisnis Dan Perikanan (Agrikan UMMU-Ternate), 3(1), 9-29.

Zeebe, R. E., \& Gladrow, D. W. (2003). $\mathrm{CO}_{2}$ in Sea Water: Equilibrium, Kinetics, Isotopes. Elsevier Journal of Chemical Information and Modeling, $53(9)$.

Zulhaniarta, D., Fauziyah., Sunaryo, A. I., \& Aryawati, R. (2015). Distribution of Chlorophyll-a Concentration To Nutrient in Banyuasin Estuary Banyuasin Regency. Maspari Journal, 7(1), 9-20.

Analisis Kelimpahan Fitoplankton di Perairan Alang-Alang Taman Nasional Karimunjawa - Nadhea Oktaviantina 
